\title{
Indirect costs in chronic obstructive pulmonary disease: A review of the economic burden on employers and individuals in the United States
}

REVIEW

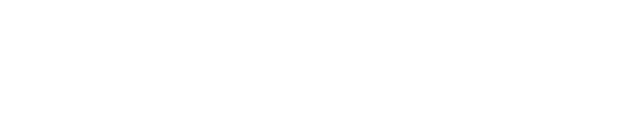

Jeetvan G Patel ${ }^{1,2}$ Saurabh P Nagar ${ }^{2}$

Anand A Dalal ${ }^{2}$

'Pharmacy Administration and Public Health, University of Houston, Houston, TX, ${ }^{2}$ US Health Outcomes, GlaxoSmithKline, Durham, NC, USA

Correspondence: Jeetvan G Patel GlaxoSmithKline, 5 Moore Drive, Bide West, Mail Stop B.3I30.3C, Durham, NC 27709, USA

$\mathrm{Tel}+\mathrm{I} 9194839852$

Fax + I 9194837932

Email jeetvan.g.patel@gsk.com
Objective: To review and summarize existing literature on the indirect burden of chronic obstructive pulmonary disease (COPD) in the US.

Methods: Medline, Scopus, and OvidSP databases were searched using defined search terms to identify relevant studies. Eligible studies were published in English between January 2000 and April 2012 and calculated the indirect burden of COPD in a US population in terms of prevalence, incidence or costs of productivity loss, disability, morbidity, or mortality.

Results: Of 53 studies identified, eleven met eligibility criteria, with data years spanning 1987-2009. Estimates of workforce participation range from 56\% to $69 \%$ among individuals with COPD and from $65 \%$ to $77 \%$ among individuals without COPD. Approximately $13 \%-18 \%$ of those with COPD are limited in the amount or type of work they can do and one-third or more experience general activity limitation. Estimates of restricted activity days range from 27-63 days per year. Estimates of mean annual sick leave and/or disability days among employed individuals with COPD range from 1.3-19.4 days. Estimates of bed confinement range from 13-32 days per year. Estimated mean annual indirect costs were \$893-\$2,234/person (US dollars) with COPD (\$1,521-\$3,348 in 2010 [US dollars]) and varied with the population studied, specific cost outcomes, and economic inputs. In studies that assessed total (direct and indirect) costs, indirect costs accounted for $27 \%-61 \%$ of total costs, depending on the population studied.

Conclusions: COPD is associated with substantial indirect costs. The disease places a burden on employers in terms of lost productivity and associated costs and on individuals in terms of lost income related to absenteeism, activity limitation, and disability. Consideration of indirect as well as direct costs is necessary to gain a more complete view of the societal burden of COPD.

Keywords: chronic obstructive pulmonary disease, disability, economics, indirect costs, productivity

\section{Introduction}

Chronic obstructive pulmonary disease (COPD) is a costly chronic disease that affects 26.8 million Americans, of whom an estimated 12 million are undiagnosed. ${ }^{1}$ Together with asthma, it is the third leading cause of death in the US. ${ }^{2}$ According to the National Heart, Lung and Blood Institute (NHLBI), the costs of COPD and asthma totaled $\$ 68.0$ billion (US dollars [USD]) in 2008, of which $\$ 53.7$ billion USD were direct costs. ${ }^{1}$ Direct costs include costs for inpatient care, physician services, prescription drugs, home health care and nursing home care. Exacerbations of COPD account for $45 \%-75 \%$ of these direct health care expenditures, as they frequently lead to physician and emergency department visits, additional medication use, and costly hospital stays. ${ }^{3}$ 
Serious exacerbations can be especially costly: in one US study, the cost of a COPD hospitalization in 2008 ranged from $\$ 7,242$ USD for a standard COPD admission to $\$ 44,909$ USD for a hospitalization involving intubation and intensive care. $^{4}$

The true burden of a disease on individuals and society is not reflected by direct costs alone, however. Indirect costs account for a substantial proportion of a disease's burden. Indirect costs are primarily related to labor force participation, including lost wages of the individual, lost wages of family caregivers, and employer-borne costs such as absenteeism and sick leave, disability, and impaired work performance (presenteeism) costs. ${ }^{5}$ Examples of other indirect costs are the costs of a hired caregiver, transportation costs, and costs associated with modifications to residences. ${ }^{5}$ Outcomes, such as activity limitation, restricted activity days, and bed days, are additional measures of a disease's indirect burden. According to NHLBI, the indirect costs of COPD- and asthma-related premature mortality (ie, productivity costs) totaled $\$ 14.8$ billion USD in 2008. ${ }^{1}$ On top of this sum is an estimated $\$ 8$ billion USD per year in indirect costs related to morbidity. ${ }^{6}$

The indirect costs of COPD have been examined from a number of angles using a variety of data sources and outcome measures. This heterogeneity of study designs, methods, and outcome measures does not permit a systematic review or meta-analysis of data that could produce definitive cost estimates. Therefore, the aim of this non-systematic review is to synthesize and summarize the existing data in order to provide an overview of the indirect costs associated with COPD.

\section{Methods}

To identify relevant published studies, searches were conducted using MEDLINE ${ }^{\circledR} /$ PubMed $^{\circledR}$, Scopus, and OvidSP databases. The search terms used were: indirect cost, productivity loss, work loss, occupational COPD, socioeconomic cost, societal cost, workforce loss, and economic burden. These terms were used in conjunction with the aforementioned terms: chronic obstructive pulmonary disease, obstructive lung disease, emphysema, and bronchitis and/or chronic bronchitis. The references cited in articles identified from the initial search were also reviewed to identify additional potentially eligible studies.

Eligible studies met the following criteria: 1) performed an original analysis of data; 2) stated the indirect burden of COPD in the US in terms of productivity, disability, costs due to morbidity or mortality, and/or lost earnings; 3) were published from January 2000 to April 2012; and 4) were published in the English language. Editorials, letters, commentary, and review articles were excluded. Original research publications were excluded if they lacked a detailed description of how COPD patients were identified for the study. Studies reporting either per-patient or national population estimates of the indirect burden of COPD were included in the review. Where estimates were stratified by COPD subtype (eg, emphysema and chronic bronchitis) or severity (eg, mild, moderate, severe) results are reported accordingly. Where appropriate, aggregate costs were converted into person-level estimates to permit comparisons across studies. Cost estimates for years prior to 2010 were inflated to 2010 USD using the annual average of the Consumer Price Index for All Urban Consumers (CPI-U; US Bureau of Labor). ${ }^{7}$ When the original study provided costs for a range of years, the final year in the range was used as the starting point for inflation adjustment.

\section{Results}

The initial search strategy produced 53 published studies of the indirect burden of COPD. After excluding 32 studies that did not meet the inclusion criteria and ten studies that met exclusion criteria, eleven studies remained within the scope of the review (Figure 1)..$^{5,8-17}$ Of these studies, eight were survey-based and three were retrospective analyses using claims data. The outcomes examined in these studies included, but were not limited to, prevalence of workforce participation, annual days of absenteeism and presenteeism, activity limitation, bed days, short-term and long-term disability, and the associated costs to the individual, employer, and/or society. Data used in these studies spanned the years 1987-2009. The studies and their characteristics are summarized in Table 1.

\section{Workforce participation}

Of the four studies that estimated workforce participation among individuals with COPD, one stratified estimates by sex and COPD type (emphysema or chronic bronchitis), ${ }^{8}$ one by comorbid asthma status, ${ }^{9}$ and one used disease severity to statistically model the impact of COPD on workforce participation (Table 2).${ }^{10}$ Self-report survey data were used for all four studies.

Using data from the 1988-1994 National Health and Nutrition Examination Survey (NHANES) III (Centers for Disease Control and Prevention, US Department of Health and Human Services, Hyattsville, MD, USA), Sin et al determined the adjusted relationship between COPD and workforce participation. ${ }^{10}$ The sample included 12,436 participants aged 18-65, of whom 1,073 had COPD and 11,363 


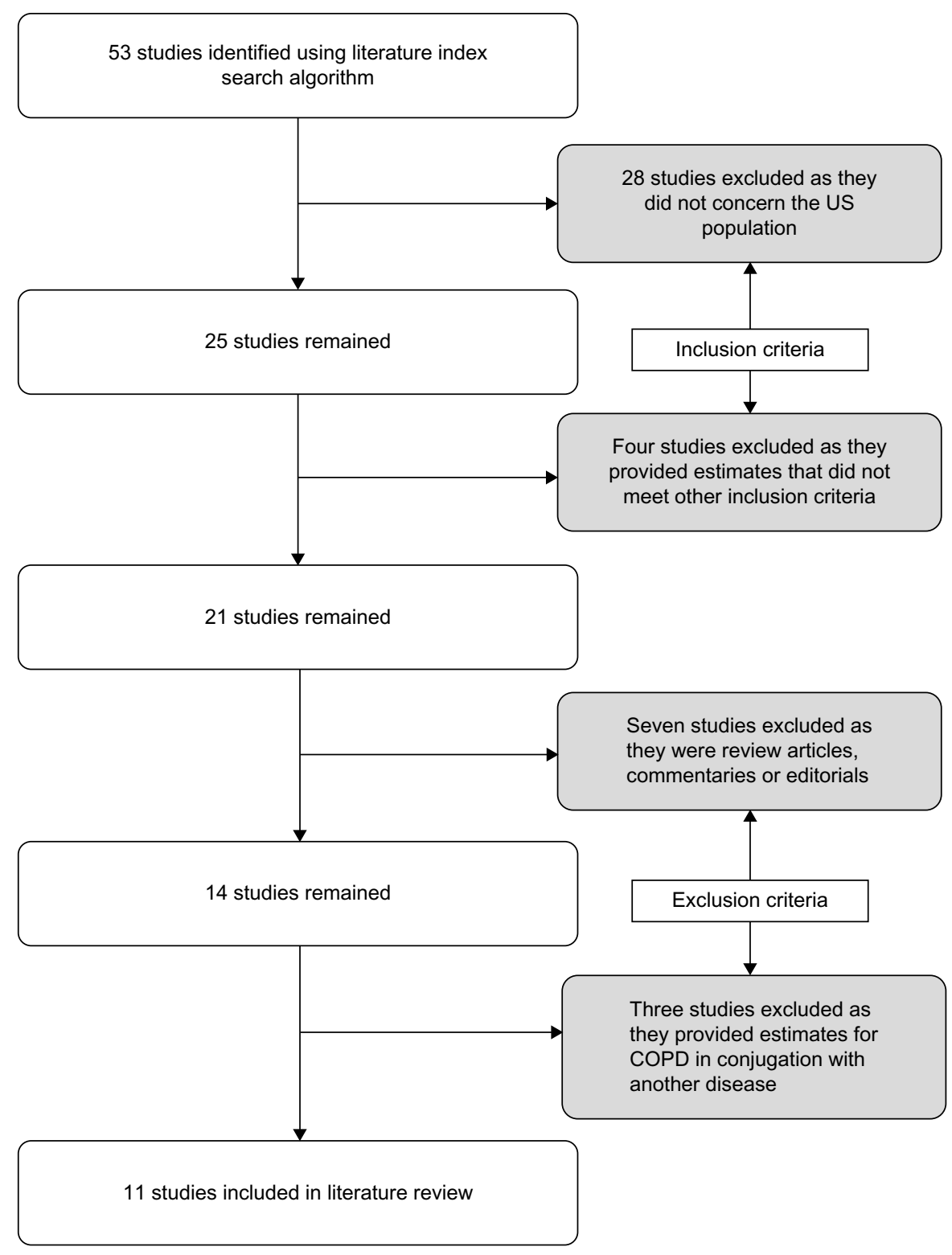

Figure I Study attrition diagram.

Abbreviation: COPD, chronic obstructive pulmonary disease

did not. Of the individuals with COPD, $69.21 \%$ reported labor force participation, compared to $77.24 \%$ of those without COPD $(P=0.001)$. Airflow obstruction in all participants was measured by spirometry. Using a Probit procedure that adjusted for age, sex, education, smoking status, and other variables, the researchers estimated that having mild, moderate, or severe COPD is associated with a $3.4 \%, 3.9 \%$, and $14.4 \%$ reduction in the workforce participation rate, respectively ( $P<0.001$ for linear trend), and demonstrated that ability to work decreases as disease severity increases; this inverse relationship is particularly pronounced for severe COPD. Altogether, participants with COPD of any severity were $3.9 \%$ less likely to be working than individuals without COPD (95\% confidence interval [CI], 1.3\%-6.4\%; $P=0.0032$ ). This study reported an $18.2 \%$ higher workforce participation for men (with or without COPD) than women (95\% CI, 16.7-19.7; $P=0.001)$.

In an analysis of combined data from the 1993 and 1994 National Health Interview Survey (NHIS), a nationally representative survey of 40,000-50,000 households per year, Ward et al found that $1.5 \%$ of 107,710 adults age $\geq 25$ years reported having chronic bronchitis $(\mathrm{n}=1,582)$ and $0.9 \%(\mathrm{n}=947)$ reported having emphysema. ${ }^{8}$ Among participants with chronic bronchitis, $18.4 \%$ said they were unable to work. However, among participants with emphysema, a much higher percentage $(62.9 \%)$ reported being unable to work. By combining the 
Table I Studies included in the review

\begin{tabular}{|c|c|c|c|c|c|}
\hline $\begin{array}{l}\text { Author and } \\
\text { publication year }\end{array}$ & $\begin{array}{l}\text { Data } \\
\text { year(s) }\end{array}$ & Study design and data source & $\begin{array}{l}\text { Primary study } \\
\text { population }\end{array}$ & $\begin{array}{l}\text { Age of study } \\
\text { population }\end{array}$ & $\begin{array}{l}\text { Category of outcomes } \\
\text { assessed }^{\text {a }}\end{array}$ \\
\hline $\begin{array}{l}\text { Strassels } \\
\text { et al, } 2001^{13}\end{array}$ & 1987 & $\begin{array}{l}\text { Cross-sectional design using } \\
\text { National Medical Expenditure } \\
\text { Survey data }\end{array}$ & Persons with COPD & $\geq 40$ years & $\begin{array}{l}\text { Absenteeism/work loss, } \\
\text { restricted activity days, bed } \\
\text { confinement days }\end{array}$ \\
\hline $\begin{array}{l}\text { Ward } \\
\text { et al, } 2002^{8}\end{array}$ & $1993-1994$ & $\begin{array}{l}\text { Cross-sectional design using SIPP } \\
\text { and National Health Interview } \\
\text { Survey data }\end{array}$ & $\begin{array}{l}\text { Persons with self- } \\
\text { reported COPD }\end{array}$ & $\geq 25$ years & $\begin{array}{l}\text { Workforce participation, work } \\
\text { limitation, absenteeism/work } \\
\text { loss }\end{array}$ \\
\hline Sin et al, $2002^{10}$ & 1994 & $\begin{array}{l}\text { Cross-sectional design using } \\
\text { NHANES III data }\end{array}$ & $\begin{array}{l}\text { Persons with COPD } \\
\text { based on spirometry }\end{array}$ & I8-64 years & $\begin{array}{l}\text { Workforce participation, } \\
\text { per person indirect costs, } \\
\text { total US costs }\end{array}$ \\
\hline $\begin{array}{l}\text { Leigh et al, } \\
2002^{16}\end{array}$ & 1996 & $\begin{array}{l}\text { Population-based cost estimates } \\
\text { using cost inputs obtained } \\
\text { from national surveys }\end{array}$ & $\begin{array}{l}\text { Estimated US } \\
\text { population with } \\
\text { occupational COPD }^{\mathrm{b}}\end{array}$ & $\geq 35$ years & $\begin{array}{l}\text { Productivity loss, morbidity } \\
\text { and mortality costs; per person } \\
\text { indirect costs, total US costs }\end{array}$ \\
\hline $\begin{array}{l}\text { Mannino } \\
\text { et al, } 2002^{9}\end{array}$ & 1996 & $\begin{array}{l}\text { Cross-sectional study using } \\
\text { NHIS data }\end{array}$ & Adults & Not provided & $\begin{array}{l}\text { Workforce participation, } \\
\text { activity limitation, absenteeism/ } \\
\text { work loss, restricted activity } \\
\text { days, bed confinement days }\end{array}$ \\
\hline $\begin{array}{l}\text { Goetzel } \\
\text { et al, } 2003^{17}\end{array}$ & $1997-1999$ & $\begin{array}{l}\text { Retrospective analysis of claims data } \\
\text { using Marketscan HPM Database } \\
\text { (data from six large employers) }\end{array}$ & $\begin{array}{l}\text { Persons with COPD } \\
\text { based on claims data; } \\
n=374,799\end{array}$ & $\geq 18$ years & $\begin{array}{l}\text { Employer costs for productivity } \\
\text { loss and disability }\end{array}$ \\
\hline $\begin{array}{l}\text { Halpern } \\
\text { et al, } 2003^{\prime \prime}\end{array}$ & 2000 & $\begin{array}{l}\text { Cross-sectional study using the } \\
\text { US subsample of the Confronting } \\
\text { COPD survey }\end{array}$ & $\begin{array}{l}\text { Persons with } \\
\text { physician-diagnosed } \\
\text { COPD }\end{array}$ & $\geq 45$ years & $\begin{array}{l}\text { Work limitation, absenteeism/ } \\
\text { work loss, per person } \\
\text { productivity loss costs }\end{array}$ \\
\hline Nair et al, $2012^{14}$ & 2000-2007 & $\begin{array}{l}\text { Retrospective case-control analysis } \\
\text { of claims data using Thomas } \\
\text { Reuters Marketscan Commercial } \\
\text { Claims Database and Health and } \\
\text { Productivity (HPM) Database }\end{array}$ & $\begin{array}{l}\text { Employed adults } \\
\text { with COPD based } \\
\text { on claims data and } \\
\text { matched controls; } \\
\mathrm{n}=27,612\end{array}$ & $18-65$ years & $\begin{array}{l}\text { Absenteeism/work loss, short- } \\
\text { term disability, per person } \\
\text { indirect costs, employer costs }\end{array}$ \\
\hline $\begin{array}{l}\text { Darkow } \\
\text { et al, } 2007^{15}\end{array}$ & $200 \mathrm{I}-2004$ & $\begin{array}{l}\text { Case-control study (matched I:2) } \\
\text { using claims from nine multi-state } \\
\text { employers }\end{array}$ & $\begin{array}{l}1,349 \text { cases with } \\
\text { primary diagnosis of } \\
\text { COPD; } 2,696 \text { controls }\end{array}$ & $40-63$ years & $\begin{array}{l}\text { Long-term disability, per } \\
\text { person indirect costs }\end{array}$ \\
\hline Wang et al, $2003^{5}$ & Not stated & $\begin{array}{l}\text { Cross-sectional analysis using World } \\
\text { Health Organization's Health and } \\
\text { Work Performance Questionnaire }\end{array}$ & $\begin{array}{l}\text { Persons with self- } \\
\text { reported COPD }\end{array}$ & $\geq 18$ years & $\begin{array}{l}\text { Disability prevalence, } \\
\text { absenteeism/work loss, } \\
\text { presenteeism }\end{array}$ \\
\hline $\begin{array}{l}\text { DiBonaventura } \\
\text { et al, } 2012^{12}\end{array}$ & 2009 & $\begin{array}{l}\text { Cross-sectional analysis using } \\
\text { self-reported data from the } 2009 \\
\text { National Health and Wellness Survey }\end{array}$ & $\begin{array}{l}\text { Employed older adults } \\
\text { with and without self- } \\
\text { reported COPD }\end{array}$ & $\geq 65$ years & $\begin{array}{l}\text { Activity limitation, absenteeism/ } \\
\text { work loss, presenteeism, } \\
\text { short-term disability }\end{array}$ \\
\hline
\end{tabular}

Notes: ${ }^{a}$ See Tables 2, 3, and 4 for more specific outcome measures; ${ }^{b}$ COPD due to occupational exposure to harmful substances, such as dust and gases.

Abbreviations: COPD, chronic obstructive pulmonary disease; NHANES III, National Health and Examination Survey III; NHIS, National Health Interview Survey; SIPP, Survey of Income and Program Participation (US Census Bureau).

chronic bronchitis and emphysema groups $(n=2,529)$, we estimate that approximately $35 \%$ of participants with any type of COPD were unable to work. This workforce participation rate for the combined groups of $65 \%$ is similar to the estimate of $69.21 \%$ obtained by Sin et al based on NHANES III data. ${ }^{10}$ Data reported by Ward et al also show that males with chronic bronchitis or emphysema had a $4.2 \%$ and $2.5 \%$ point higher rate of inability to work, respectively, than did females. ${ }^{8}$ In the 1996 NHIS, $5.9 \%$ of adults age $\geq 25$ years reported having COPD. ${ }^{9}$ Mannino's age-adjusted estimates indicated that $54 \%$ of participants with both COPD and asthma and $56 \%$ of those with COPD alone were working, compared to $65 \%$ of participants with no COPD or asthma.
The inability to work that is attributable to COPD (rather than to any cause) was examined in two studies, both of which used self-report survey data. Halpern et al evaluated data from the US sample of the multi-country Confronting COPD survey, a telephone survey of individuals with COPD conducted in 2000. ${ }^{11}$ The age of the 447 US respondents ranged from 42 to 89 years with a mean of 64 years; $40 \%$ had mild disease, $52 \%$ moderate disease, and $7 \%$ severe disease. A total of $34 \%$ reported being unable to work because of COPD.

The NHIS analysis by Ward et al presents the percentages of individuals with COPD with "inability to work attributable to respiratory conditions" separately from the "inability to work" figures cited above and reported values of $0.6 \%$ and 
Table 2 Proportion of individuals with COPD reporting productivity impairment: ability to work, work and activity limitations, and disability

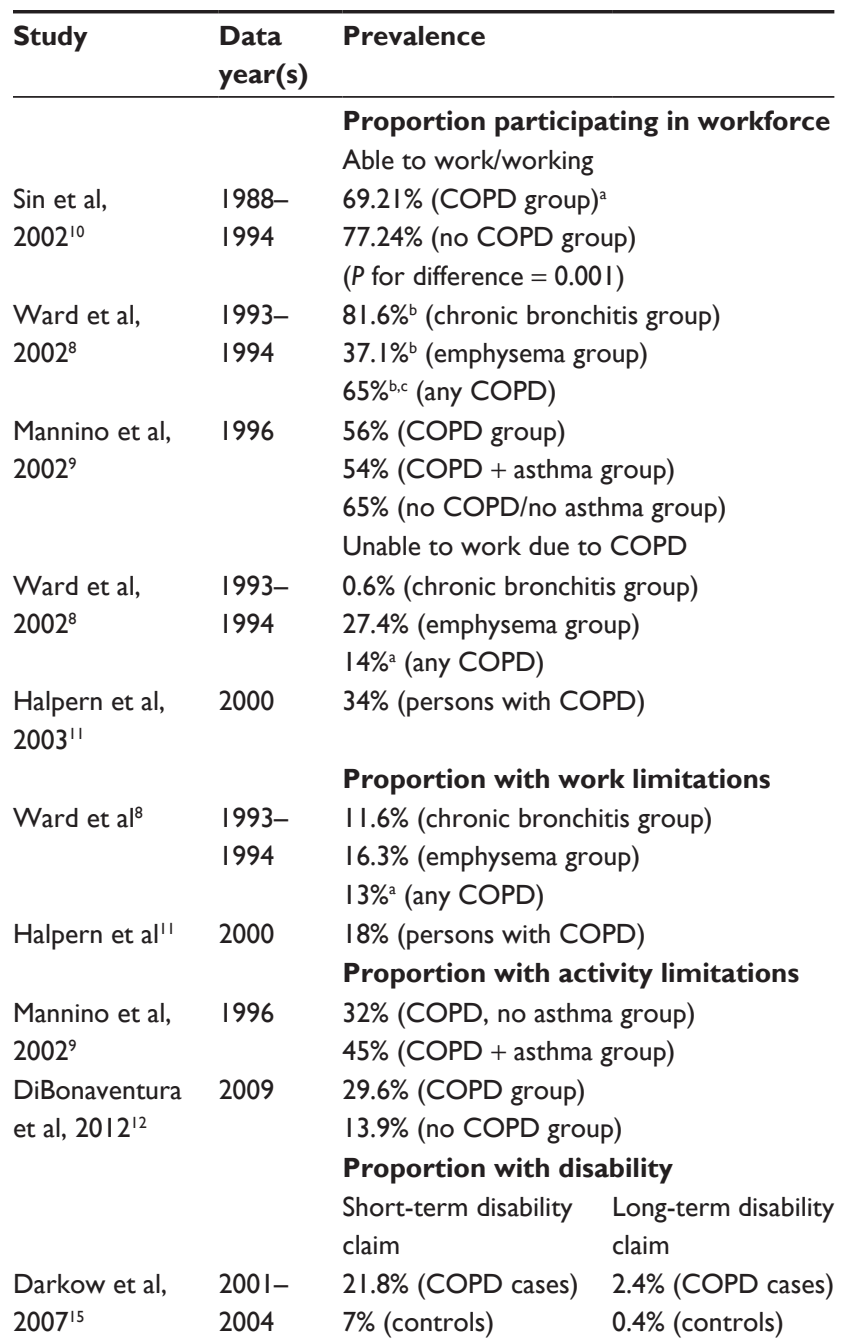

Notes: aln a logistic regression model that adjusted for age, sex, education, smoking status and other variables, having mild, moderate or severe COPD was associated with a $3.4 \%, 3.9 \%$, and $14.4 \%$ reduction in the workforce participation rate, respectively $(P<0.00$ I for linear trend); b the study publication presents results as the proportion of the sample unable to work/not working as follows: 18.4\% (chronic bronchitis), $62.9 \%$ (emphysema), 35\% (chronic bronchitis or emphysema). We have subtracted these proportions from I to report the inverse value (proportion able to work/working) in order to facilitate comparison across studies; 'Values for the combined chronic bronchitis and emphysema groups were calculated by the authors using data provided in the publication.

Abbreviation: COPD, chronic obstructive pulmonary disease.

$27.4 \%$ for the chronic bronchitis and emphysema groups, respectively. ${ }^{8}$ In our calculation, if the chronic bronchitis and emphysema groups are combined, the percentage of participants with inability to work attributable to respiratory conditions is approximately $14 \%$, a much lower figure than that derived by Halpern et al from the Confronting COPD survey. ${ }^{11}$ Mannino et al and Sin et al present the percentage of participants with and without COPD who were working, but for those not working, the cause of that status is not pro- vided. ${ }^{9,10}$ Additional research is needed to clarify this aspect of the indirect burden of COPD.

Although the survey questions and workforce participation outcomes reported in these studies may not be strictly equivalent, taken together, the data suggest that the prevalence of workforce participation among individuals with COPD is approximately $56 \%-69 \%$, compared to $65 \%-77 \%$ of individuals without COPD. These estimates are similar to the finding of a study of clinic patients with COPD, which found that $60 \%$ were able to work. ${ }^{18}$ Emphysema, more severe disease, and possibly comorbid asthma are more likely to be associated with inability to work than are chronic bronchitis or mild disease.

\section{Work limitations}

Data from two studies that used self-report survey data indicate that approximately $13 \%-18 \%$ of working individuals with COPD experience limitations regarding their work (Table 2) ${ }^{8,11}$ In Ward et al's analysis of 1993-1994 NHIS data, $11.6 \%$ of participants with chronic bronchitis and $16.3 \%$ of those with emphysema reported they were limited in the kind or amount of work they could perform. ${ }^{8}$ By combining both groups using group numbers provided in the publication, we estimate that $13 \%$ of all survey participants with COPD had work limitations. A total of $3.4 \%$ of individuals with chronic bronchitis and $43.5 \%$ of those with emphysema attributed their work limitations to their condition. In Halpern et al's review of the US sample of the Confronting COPD survey, $18 \%$ of respondents reported they were "limited in their ability to work normally". ${ }^{11}$

\section{Absenteeism and presenteeism}

Estimates of absenteeism in employed individuals with COPD vary from 1.3 to 19.4 days per year across seven studies (Table 3). ${ }^{5,8,9,11-14}$ This wide variation is due in part to the fact that some studies report total days of absenteeism (due to any cause) and others report excess absenteeism due to COPD alone. In addition, at least one study included vacation days in its absenteeism estimates, whereas other studies included only sick days and disability days. In some cases, the definition of absenteeism or work loss days is unclear.

Using data from the 1987 National Medical Expenditure Survey (NMES), a survey of 14,000 households and about 35,000 individuals, Strassels et al found that among 238 individuals age $\geq 40$ years with COPD, the number of mean lost workdays per year was 3.6 (95\% CI, 1.4-5.8), of which $38 \%$ were COPD-related ( 1 day, $95 \% \mathrm{CI}<0.1-2.0) .{ }^{13}$ This survey oversamples for low-income families, black and 
Table 3 Days per year: work loss, disability, and bed confinement in persons with COPD

\begin{tabular}{|c|c|c|}
\hline Study & $\begin{array}{l}\text { Base } \\
\text { year }\end{array}$ & $\begin{array}{l}\text { Mean days per year } \\
\text { (patient subgroup) }\end{array}$ \\
\hline & & Absenteeism/work loss days \\
\hline $\begin{array}{l}\text { Strassels } \\
\text { et al, }\left.200\right|^{13}\end{array}$ & 1987 & $\begin{array}{l}\text { I.0 COPD-related (COPD group) } \\
3.6 \text { all cause (COPD group) }\end{array}$ \\
\hline $\begin{array}{l}\text { Ward } \\
\text { et al, } 2002^{8}\end{array}$ & $\begin{array}{l}1993- \\
1994\end{array}$ & $\begin{array}{l}\text { I.5 (chronic bronchitis group) } \\
\text { I.3 (emphysema group) }\end{array}$ \\
\hline et al, $2002^{9}$ & 1996 & $\begin{array}{l}2.4 \text { (COPD group) } \\
8.2 \text { (COPD + asthma group) } \\
2.9 \text { (no COPD/no asthma group) }\end{array}$ \\
\hline $\begin{array}{l}\text { Halpern } \\
\text { et al, } 2003^{\prime \prime}\end{array}$ & 2000 & $\begin{array}{l}2.9 \text { (no COPD/no asthma group) } \\
18.7^{\mathrm{b}} \text { (COPD group) } \\
1.7 \text { (caregivers) }\end{array}$ \\
\hline \multirow[t]{2}{*}{$2012^{14}$} & $\begin{array}{l}2000 \\
2007\end{array}$ & $\begin{array}{l}0.3 \text { hours/month, COPD-related (COPD group) } \\
5.6 \text { hours/month, all cause (COPD group) }\end{array}$ \\
\hline & & 3.8 hours/month, all cause (no COPD group) \\
\hline $\begin{array}{l}\text { DiBonaventura } \\
\text { et al, } 2012^{12}\end{array}$ & 2009 & $\begin{array}{l}1.88 \text { hours in past } 7 \text { days (COPD group) } \\
0.77 \text { hours in past } 7 \text { days (no COPD group) }\end{array}$ \\
\hline \multirow[t]{2}{*}{$\begin{array}{l}\text { Wang } \\
\text { et al, } 2003^{5}\end{array}$} & $\begin{array}{l}\text { Not } \\
\text { stated }\end{array}$ & $19.4^{\mathrm{b}, \mathrm{c}}$ (persons with COPD) \\
\hline & & Presenteeism days \\
\hline $\begin{array}{l}\text { Wang } \\
\text { et al, } 2003^{5}\end{array}$ & $\begin{array}{l}\text { Not } \\
\text { stated }\end{array}$ & $27.5^{c}$ (persons with COPD) \\
\hline \multirow[t]{2}{*}{ et al, $2012^{12}$} & 2009 & $\begin{array}{l}4.82 \text { hours in past } 7 \text { days (COPD group) } \\
2.59 \text { hours in past } 7 \text { days (no COPD group) }\end{array}$ \\
\hline & & Short-term disability days \\
\hline $\begin{array}{l}\text { Darkow } \\
\text { et al, } 2007^{15}\end{array}$ & $\begin{array}{l}2001- \\
2004\end{array}$ & $\begin{array}{l}54.8 \text { (COPD cases) } \\
39.1 \text { (controls) }\end{array}$ \\
\hline \multirow[t]{3}{*}{$2012^{14}$} & $\begin{array}{l}2000- \\
2007\end{array}$ & $\begin{array}{l}0.3 \text { days/month, COPD-related (COPD group) } \\
1.0 \text { days/month, all cause (COPD group) }\end{array}$ \\
\hline & & 0.6 days/month, all cause (no COPD group) \\
\hline & & Long-term disability days \\
\hline et al, $2007^{15}$ & $\begin{array}{l}2001- \\
2004\end{array}$ & $\begin{array}{l}76.4 \text { (COPD group) } \\
85.9 \text { (controls) }\end{array}$ \\
\hline Strassels & 1987 & $\begin{array}{l}\text { Restricted activity days } \\
\text { I5.9 COPD-related }\end{array}$ \\
\hline et al, $200 I^{13}$ & & 27.5 all cause \\
\hline Mannino, & 1996 & 31.0 (COPD group) \\
\hline \multirow[t]{3}{*}{$2002^{9}$} & & 62.5 (COPD + asthma group) \\
\hline & & I5.3 (no COPD/no asthma group) \\
\hline & & Bed confinement days \\
\hline $\begin{array}{l}\text { Strassels } \\
\text { et al, } 200 \mathrm{I}^{13}\end{array}$ & 1987 & $\begin{array}{l}\text { 16.I COPD-related (COPD group) } \\
24.4 \text { all cause (COPD group) }\end{array}$ \\
\hline Mannino, & 1996 & I3.I (COPD group) \\
\hline \multirow[t]{2}{*}{$2002^{9}$} & & 31.5 (COPD + asthma group) \\
\hline & & 6.I (no COPD/no asthma) \\
\hline
\end{tabular}

Notes: ${ }^{a}$ Except as otherwise noted; ${ }^{b}$ includes vacation days; 'value represents excess days due to COPD.

Abbreviation: COPD, chronic obstructive pulmonary disease.

Hispanic individuals, the elderly and functionally impaired persons, as its primary purpose is to inform health care policy decisions.

In Ward et al's study of 1993-1994 NHIS data, less than $5 \%$ of participants with COPD reported any work loss days in the past two weeks and work loss averaged 1.5 days per year for chronic bronchitis and 1.3 days per year for emphysema. ${ }^{8}$
Mannino et al analyzed 1996 NHIS data and reported an average annual work loss of 8.2 days for participants with COPD and asthma and 2.4 days for those with COPD alone, compared to 2.9 days for those with neither COPD nor asthma. ${ }^{9}$

In a study of employed adults age 65 and older, selfreported absenteeism during the past seven days was 0.75 hours among adults without COPD $(n=3,061)$ but 1.08 hours among adults with COPD $(\mathrm{n}=297)$, which is roughly equivalent to 7 days per year if one assumes absenteeism rates are constant throughout the year. ${ }^{12}$ After adjustment for demographic and health history variables, however, the difference in absenteeism between those with and without COPD was not statistically significant.

In the Confronting COPD Survey, $6 \%$ of 447 US respondents of working age reported in 2000 that they had missed work due to COPD over the last 12 months, and absenteeism averaged 18.7 days. ${ }^{11}$ To assess the impact of chronic health conditions on work performance, Wang et al administered the World Health Organization's Health and Work Performance Questionnaire (WHO-HPQ) by telephone to four populations of workers age 18 years and older $(n=2,350) .{ }^{5}$ Among the $1.7 \%$ of participants with COPD, excess absenteeism due to COPD averaged 19.4 days (standard error 8.9), excess presenteeism (lost productivity due to underperformance while at work) averaged 27.5 days (standard error 15.6), and excess absenteeism and presenteeism combined averaged 42.9 days (standard error 17.0) annually. Although the standard error for these values is large due to small sample size, these effect sizes were larger for COPD than for the other 12 chronic conditions evaluated. Having COPD was a significant predictor of absenteeism, but not presenteeism. Absenteeism included all time away from work, including vacation, sick leave, and disability, which may explain the high number of work loss days compared to other studies of COPD-related work loss. Taken together, these seven studies yield fairly disparate estimates of work loss in persons with COPD.

\section{Family caregivers}

Spouses and other family members may provide care for individuals with COPD and, if employed, may sometimes miss work in order to do this. These are additional work loss costs. One study examined work loss among family caregivers based on self-report survey data. ${ }^{11} \mathrm{~A}$ total of 7\% of participants with COPD reported some work loss for a family member, with an average work loss of 1.7 days per family caregiver per year. 


\section{Activity limitation, bed confinement, and disability}

Five studies looked at COPD-related activity limitation, bed confinement days, short-term disability or long-term disability. Prevalence estimates for these conditions are shown in Table 2 and estimates of annual days are shown in Table 3.

\section{Activity limitation}

In the 1997 NHIS, $32 \%$ of individuals with COPD alone and $45 \%$ of individuals with COPD and asthma reported some activity limitation. ${ }^{9}$ The COPD group experienced a mean of 31.0 restricted activity days annually and the COPD + asthma group experienced 62.5 restricted activity days. The NMES analysis by Strassels et al of 228 individuals with COPD found that out of 27.5 mean total restricted activity days, $58 \%$ (15.9 days, $95 \%$ CI $10.3-21.5$ ) were COPD-related. ${ }^{13}$ Using National Health and Wellness Survey data, DiBonaventura reported that $29.9 \%$ of those with COPD had some activity limitation, compared to $13.9 \%$ of those without COPD. ${ }^{12}$

\section{Bed days}

Two studies reported annual days of bed confinement. In Mannino et al's analysis of 1996 NHIS data, individuals with COPD alone reported 13.1 bed days and those with COPD + asthma reported 31.5 bed days per year. ${ }^{9}$ These figures are of a similar magnitude to those reported by Strassels et al based on 1987 NMES data. ${ }^{13} \mathrm{He}$ found that respondents with COPD had 24.4 (95\%CI, 20.5-34.4) total bed days; however, only 16.1 bed days $(95 \% \mathrm{CI}, 10.3-21.8)$ were COPD-related. Thus, estimates of bed confinement range from about 13 to 32 days per year for people with COPD and the number of excess bed days due to the disease itself may be somewhat or considerably less.

\section{Disability prevalence and related work loss}

Using a health care claims and disability database with data for nine multi-state companies employing 550,000 individuals (age 40-63 years), Darkow et al estimated the rate and duration of short-term and long-term disability. ${ }^{15}$ They identified 1,349 employees (mean age, 52 years) with a primary diagnosis of COPD based on healthcare claims in 2001-2004 and matched them to 2,696 controls without COPD. A total of $21.8 \%$ of employees with COPD had a short-term disability claim for any cause compared to $7.0 \%$ of controls, and $2.4 \%$ had a long-term disability claim for any cause compared to $0.4 \%$ of controls. In an analysis that adjusted for length of follow-up and comorbidities not related to COPD, employees with COPD were twice as likely to have a short-term disability claim (odds ratio [OR] 2.11,95\%CI 1.64-2.71) and more than four times as likely to have a long-term disability claim (OR 4.21, 95\%CI 1.93-9.16) as controls. In an adjusted analysis, cases had $54.8(95 \%$ CI 49.5-60.1) short-term disability days versus 39.1 (95\%CI 32.5-45.7) for controls and 76.4 (95\% CI 56.4-96.4) long-term disability days versus 85.9 (95\% CI 48.7-123.1) for controls.

In a study based on claims data for employees age 18 to 65 years, of whom $2.9 \%$ had COPD, a mean of 5.6 absence hours and 1.0 short-term disability hours per month occurred in employees with COPD and 3.8 absence hours and 0.6 shortterm disability days occurred in the comparison group. ${ }^{14}$

\section{Costs of COPD-related productivity loss, activity limitation, and disability}

The indirect costs of COPD have been estimated in terms of productivity losses stemming from absenteeism and disability. These have been calculated using wage, fringe benefits, short-term and long-term disability payments, and other cost inputs. Our search strategy identified six studies that calculated these indirect costs of COPD. Per-person cost estimates are shown in Table 4. Both the costs presented in each publication for the relevant study year and those same costs inflated to 2010 USD are presented. Costs for the US population are shown in Table 5.

Using the 3.9\% reduction in the work participation rate among people with COPD and the population weights derived from NHANES III data, Sin et al estimated that among a total COPD population of $\sim 9.4$ million persons in 1994, there was excess unemployment of 366,600 persons (due to COPD), which represents a productivity loss of $\$ 9.9$ billion USD per year $(366,600 \times \$ 27,193$, where $\$ 27,193$ is the average US wage plus fringe benefits [US Department of Labor])..$^{10}$ Distributing this cost across the entire 1994 US COPD population yields a mean lost productivity cost of $\$ 1,053$ USD per person with COPD ( $\$ 9.9$ billion $\div 9.4$ million persons).

Leigh et al estimated the 1996 indirect mortality and morbidity costs of occupational COPD based on the assumption that COPD due to work exposures represents $15 \%$ of all COPD cases ( $15 \%$ is the population attributable risk [PAR]). ${ }^{16}$ National Center for Health Statistics life-table estimates and US Bureau of Labor Statistics labor force participation data were used to estimate the per-person mean cost of wages, fringe benefits and home production for years of life lost due to early death. These same inputs were used to estimate indirect morbidity costs for persons who were partially or fully disabled due to occupational COPD. For both estimates, perperson costs were multiplied by the estimated US prevalence 
Table 4 Costs associated with the indirect burden of COPD

\begin{tabular}{|c|c|c|c|c|}
\hline Study & Base year & Outcome measure & Reported cost & Cost inflated to 2010 USD $^{\mathrm{a}}$ \\
\hline \multicolumn{5}{|c|}{ Mean cost per person affected by the condition of interest } \\
\hline \multirow[t]{2}{*}{ Nair et al, $2012^{14}$} & 2000-2007 & Mean annual indirect expenditures & $\$ 909$ (case) versus & $\$ 1,016$ (case) versus \\
\hline & & & $\$ 3,609$ (control) & $\$ 4,032$ (control) \\
\hline \multirow[t]{2}{*}{ Darkow et al, $2007^{15}$} & $200 \mathrm{I}-2004$ & Mean annual all-cause disability cost per case & $\$ 9,815$ (case) versus & $\$ 14,130$ (case) versus \\
\hline & & (COPD) or control with disability claim & $\$ 6,335$ (control) & $\$ 9,121$ (control) \\
\hline \multicolumn{5}{|c|}{ Mean cost per person for total COPD population } \\
\hline \multirow[t]{3}{*}{ Leigh et al, $2002^{16}$} & 1996 & $\begin{array}{l}\text { Mean annual mortality (lost productivity) costs for } \\
\text { occupational COPD }\end{array}$ & $\$ 526^{\mathrm{b}}$ & $\$ 896$ \\
\hline & & Mean annual morbidity costs for occupational COPD & $\$ 376^{b}$ & $\$ 640$ \\
\hline & & Total mean indirect costs for occupational COPD & $\$ 893^{\mathrm{b}}$ & $\$ 1,521$ \\
\hline Halpern et al, $2003^{\prime \prime}$ & 2000 & Mean annual indirect costs & $\$ 1,527$ & $\$ 2,289$ \\
\hline Darkow et al, $2007^{15}$ & $200 I-2004$ & Mean annual disability costs & $\$ 2,234^{b}$ & $\$ 3,348$ \\
\hline \multicolumn{5}{|c|}{ Employer cost per employee ${ }^{c}$} \\
\hline \multirow[t]{2}{*}{ Goetzel et al, $2003^{17}$} & $1997-1999$ & Mean annual COPD-related absence payment & $\$ 22.62$ & $\$ 37.22$ \\
\hline & & $\begin{array}{l}\text { Mean annual COPD-related short-term } \\
\text { disability payment }\end{array}$ & $\$ 5.21$ & $\$ 8.57$ \\
\hline \multirow[t]{2}{*}{ Nair et al, $2012^{14}$} & $2000-2007$ & Mean annual COPD-related absence payment & $\$ 55$ & $\$ 61$ \\
\hline & & Mean annual COPD-related disability payment & $\$ 527$ & $\$ 589$ \\
\hline
\end{tabular}

Notes: anflated using medical care component of the Consumer Price Index; ${ }^{b}$ calculated by authors using data provided in publication; ${ }^{\mathrm{C}}$ denominator is all employees. COPD prevalence in this employed population was $3.5 \%$.

Abbreviations: COPD, chronic obstructive pulmonary disease; USD, US dollars.

of occupational COPD (in 1996, there were an estimated $14,150,000$ persons with chronic bronchitis and 1,821,000 persons with emphysema, which summed and multiplied by $15 \%$ yielded an estimated 2,395,650 persons with occupational COPD). Lost earnings, fringe benefits and home production costs totaled $\$ 0.8793$ billion USD for mortality and $\$ 1.2607$ billion USD for morbidity, for an estimated total indirect cost of $\$ 2.14$ billion USD for occupational COPD in 1996. Although Leigh et al do not provide per-person costs, dividing the national prevalence of occupational COPD used in the study by the total population costs they calculated produces an estimated annual per-person indirect cost of $\$ 893$ USD for mortality and morbidity combined ( $\$ 367$ USD for mortality plus \$526 USD for morbidity).
Halpern et al estimated the mean annual productivity cost to be $\$ 1,527$ USD per person with COPD (in 2000) based on work loss figures from the Confronting COPD survey. The estimate was based on a mean of 18.7 lost work days for the 25 individuals who reported work loss and a cost per day of $\$ 100.55$ USD (for employees age 45 years to retirement). ${ }^{11}$

In the retrospective case-control study of employed individuals with COPD described above, Darkow et al calculated disability costs for persons with COPD using data from January 1, 2001 to March 31, 2004..$^{15}$ Total lost work days due to short-term and long-term disability (adjusted for length of follow-up) were multiplied by that employee's daily wage. Mean annualized disability costs, adjusted for length of follow-up (which ranged from 90 to 365 days) were

Table 5 Estimates of the annual indirect costs of COPD in the US

\begin{tabular}{|c|c|c|c|c|}
\hline Study & Base year & Indirect cost measure & Study result & Value in 2010 USD $^{a}$ \\
\hline Sin et al, $2002^{10}$ & $1988-1994$ & Productivity loss & $\$ 9.9$ billion & $\$ 18.5$ billion \\
\hline \multirow[t]{4}{*}{ Leigh et al, $2003^{16}$} & 1999 & Lost earnings & $\$ 1.57$ billion & $\$ 2.44$ billion \\
\hline & & Lost fringe benefits & $\$ 0.36$ billion & $\$ 0.56$ billion \\
\hline & & Lost home earnings $\mathrm{s}^{\mathrm{b}}$ & $\$ 0.21$ billion & $\$ 0.33$ billion \\
\hline & & Total lost earnings and fringe benefits & $\$ 2.14$ billion & $\$ 3.32$ I billion \\
\hline \multirow[t]{3}{*}{ Leigh et al, $2003^{16}$} & 1999 & Morbidity & $\$ 1.26$ billion & $\$ 1.957$ billion \\
\hline & & Mortality & $\$ 0.88$ billion & $\$ 1.374$ billion \\
\hline & & Total morbidity and mortality & $\$ 2.14$ billion & $\$ 3.321$ billion \\
\hline NHLBI, $2009^{6}$ & Various & Projected 2010 morbidityc & $\$ 8.0$ billion & $\$ 8.0$ billion \\
\hline NHLBI, 20I2' & & 2008 premature mortality ${ }^{c}$ & $\$ 14.8$ billion & $\$ 15.0$ billion \\
\hline
\end{tabular}

Notes: ${ }^{a}$ Study values were inflated to USD 2010 value using medical care component of the Consumer Price Index; blost productivity related to home tasks such as child care, home repair, meal preparation, etc; 'included for comparative purposes.

Abbreviations: COPD, chronic obstructive pulmonary disease; NHLBI, National Heart, Lung and Blood Institute; USD, US dollars. 
$\$ 9,815$ USD $(95 \%$ CI $\$ 83,84-\$ 11,246)$ for employees with COPD who had disability claims $(22.8 \%, \mathrm{n}=307)$ and $\$ 6,335$ $(95 \%$ CI $\$ 4,541-\$ 8,130)$ for employees without COPD who had disability claims $(7.3 \%, \mathrm{n}=197)$. By dividing total disability costs (307 cases $\times \$ 9,815$ USD) by the total number of employees with COPD (both with and without disability claims; $n=1,349$ ), we arrive at a mean cost of $\$ 2,234$ USD per employee with COPD, compared to \$463 USD per employee without COPD $(n=2,696)$. Thus, we roughly estimate the excess cost of disability for COPD in this employed population to be $\$ 1,771$ USD per year.

Data for 374,799 employees of six large employers, derived from the MEDSTAT Group's MarketScan HPM database, were used to evaluate the indirect costs of COPD and other physical and mental health conditions in 1999. ${ }^{17}$ Costs for absenteeism were calculated by multiplying the hours absent by $\$ 30.00$ USD (representing hourly wages and fringe benefits).

Goetzel points out that even the $\$ 23.15 /$ hour USD rate (average wages plus benefits) produced by the US Bureau of Labor statistics is likely to undervalue labor time, because it considers only wages and fringe benefits. Employers engender additional costs, however, including the cost of over-staffing to compensate for absenteeism and costs related to the "spillover effect", which is the impact on the productivity of a team that occurs when one member is absent. The mean annual absence payment per employee with COPD was $\$ 22.62$ USD and the mean short-term disability payment, based on claim amounts, was $\$ 5.21$ USD (for claims with missing costs, the cost per day was imputed based on $60 \%$ of \$144 USD, the estimated value of a day of work), yielding a total mean cost of \$27.83 USD. Similar outcomes reported by Nair et al included mean annual absence payments of $\$ 55$ USD (COPD-related absences) and \$1,104 USD (all-cause absences) among individuals with COPD compared to $\$ 0$ USD and \$742 USD among individuals without COPD. ${ }^{14}$ The adjusted difference in all-cause absence payments was $\$ 155$ USD. All-cause short-term disability payments ( $\$ 1,608$ USD for employees with COPD; \$981 USD for employees without COPD) yielded an adjusted difference of \$754 USD.

\section{Indirect costs as a percentage of total costs}

In the study of productivity costs in employed adults by Goetzel et al, absence and disability costs in persons with COPD accounted for $43 \%$ of the employer's total health and productivity costs. ${ }^{17}$ Leigh et al report a similar rate in adults age 35 and older (employed and unemployed), with indirect costs accounting for $44 \%$ of total costs in persons with occupational COPD. ${ }^{16}$ The study by Nair et al of employed adults, which used both commercial claims and large employer productivity databases, reported that indirect costs represented $61 \%$ of total COPD-related costs. ${ }^{14}$ In contrast, in the Confronting COPD Survey, work loss accounted for $27 \%$ of total costs in adults age 45 and older. ${ }^{11}$ This lower percentage may be attributable to the sample population, which including both working age and older adults; older adults would not be expected to contribute as much to workrelated categories of indirect costs, such as absenteeism and disability claims. According to NHLBI, which estimated direct, premature mortality, and morbidity costs based on data from various national surveys, the projected proportion of indirect costs for COPD in 2010 was $41 \%{ }^{6}$

\section{Key results summary}

- Estimates of the prevalence of workforce participation among individuals with COPD ranged from $56 \%$ to $69 \%$, compared to $65 \%$ to $77 \%$ among individuals without COPD.

- Among employed individuals with COPD, absenteeism ranged from 1.3-19.4 days (higher estimates included vacation/annual leave days in addition to sick leave and/ or disability days).

- Approximately $13 \%$ to $18 \%$ of persons with COPD reported they were limited in the amount or type of work they could do. One-third or more of individuals with COPD reported general activity limitation. Individuals with COPD who have emphysema (rather than chronic bronchitis) or comorbid asthma were more likely to experience activity limitation. Estimates of restricted activity days ranged from 27.5 to 62.5 days per year. The number of bed confinement days ranged from 13 to 32 days per year.

- Estimated mean annual indirect costs ranged from $\$ 893$ to $\$ 2,234$ USD/person with COPD in 1994-2004 dollars, or $\$ 1,521$ to $\$ 3,348$ USD per person in 2010 dollars, with estimates varying based on the population studied, specific cost outcomes calculated and the economic inputs used.

- Indirect costs accounted for $27 \%$ to $61 \%$ of total costs, with the higher estimates produced by studies of working age populations. ${ }^{6}$

\section{Discussion}

Based on national survey data, the costs of COPD in the United States have been estimated to be $\$ 49.9$ billion USD per year, with indirect costs accounting for approximately $41 \%$ of total costs. ${ }^{1,6}$ In this review, we summarized studies that 
examined various components of indirect costs. The findings of reduced workforce participation, increased absenteeism and disability, and activity limitations among persons with COPD are not surprising and probably reflect the symptomatic component of COPD, which includes fatigue, exertion dyspnea, chronic cough, and wheeze, and more frequent respiratory infections. In addition, periodic acute exacerbations of COPD often require treatment on an outpatient or inpatient basis, necessitating absence from work. Chronic obstructive pulmonary disease is a progressive disease, and as Sin et al have shown, labor force participation decreases as disease severity increases. ${ }^{10}$ Although only one study examined outcomes by COPD subtype, it found that productivity losses were substantially higher for individuals with emphysema than for individuals with chronic bronchitis. ${ }^{8}$

Although estimates of productivity losses associated with COPD varied, it is clear that COPD has a significant impact on individuals and employers in terms of work loss, disability, activity limitation, and bed confinement days, and this impact results in a substantial indirect cost burden.

It also should be noted that comorbidities contribute to the total burden of COPD, since this systemic disease has serious adverse effects that go well beyond the lungs. Many individuals with COPD have asthma, cardiovascular disease, hypercholesterolemia, hypertension, depression, cataracts, osteoporosis, and/or diabetes. ${ }^{19}$ Studies have shown that co-morbid depression and cardiovascular disease have a substantial impact on the direct costs of COPD. ${ }^{20,21}$ It is likely that these and other comorbidities contribute to the indirect costs of COPD as well.

Can the indirect burden of COPD be reduced? Good disease management can improve quality of life and decrease resource use and costs. ${ }^{22-24}$ Pharmacotherapy, smoking cessation, pulmonary rehabilitation, and certain surgical procedures have been shown to alter disease progression. ${ }^{25}$ Thus, initiation of appropriate medication therapy, smoking cessation support, and referral to pulmonary rehabilitation programs in the clinic setting could lead to improved work productivity. In the workplace setting itself, smoking cessation programs are one strategy that can be readily implemented by employers. Coordination of efforts by employers and health care providers might further improve COPD management and reduce the disease's impact on individuals, families, and employers.

\section{Limitations}

The studies we reviewed assessed indirect costs from the US perspective and cannot be generalized to other countries, which have different health care systems (including different insurance systems), productivity impacts and measurement methods, and workplace illness policies and benefits. Several studies in this review used data sources that identified individuals with COPD based on self-report. Because nearly half of individuals with COPD, especially those with mild symptoms, are undiagnosed, data based on self-report may underestimate COPD prevalence and hence the estimates of disease burden and cost, as is suggested by the results of the Confronting COPD Survey. ${ }^{15}$ In interpreting findings, it must be kept in mind that the percentage of total costs attributable to indirect costs is likely to be higher in working age compared to older populations, since the majority of indirect costs are derived from measures of productivity loss. In addition, as COPD is a progressive disease, direct medical costs may be relatively higher and indirect costs relatively lower in older age groups. Thus, the indirect burden of COPD (both the per capita and total population burden) identified in a single study must be viewed in the context of the population sample studied and the findings may not reflect the burden in the entire COPD population.

\section{Research needs}

To obtain a complete picture of the societal impact of a chronic condition, indirect costs have to be considered along with the more easily quantified direct costs. Limited data sources are available for measuring indirect costs at a population level, and estimates of indirect costs in COPD have not been as consistent as have estimates of direct costs. This is due in part to differences in measures that capture worker productivity, absenteeism, presenteeism, short-term disability, and worker compensation across various populations. Survey methods also have inherent biases, such as responder bias and recall bias. In addition, productivity measured in wage-earning industries has a different complexion than productivity among salaried workers, making the measurement and attribution of indirect costs to a particular disease or condition more difficult. It is challenging to calculate the true burden of the disease on a population level because of this imperfectly-captured data. Therefore, productivity and other indirect costs may be underreported and/or underestimated in many cases.

In addition to methodological and logistical issues that may result in inadequate capture of indirect cost data, other research gaps are evident in the literature. The majority of indirect cost analyses are based on data from the 1980s and 1990s, and analyses using more recent data are needed. The management of COPD has improved in the last decade, 
particularly in terms of pharmacotherapy management, new classes of medications, and the use of evidence-based clinical guidelines. Analysis of more recent data may show that these changes have had a positive impact on productivity losses. Health services and outcomes research methods also have evolved considerably over the years with the development of more effective approaches to data collection, management of confounding biases, and calculation of indirect costs. Some large employers have now started systematic collection and reporting of employee productivity claims.

Currently, little is known about the burden of COPD on families or caregivers. Leigh et al have pointed out that these costs may be difficult to estimate, but based on prior research about "informal" caregiving, they are probably large. ${ }^{16}$ Nationally representative surveys employing complex sampling weights have been developed which report the productivity burden of the caregiver as well as the patient.

Incremental indirect costs associated with COPD need to be evaluated, especially among low-risk patients who are not experiencing frequent COPD exacerbations. These patients would be expected to be relatively younger and more likely to be in the workforce than higher-risk patients with more frequent exacerbations, thus having a higher productivity loss burden. ${ }^{26}$

In order to develop estimates that are more interpretable and meaningful, studies employing a matched control group of patients with similar disease severity could be employed. In the current literature, only a few studies identifying COPDrelated productivity loss or indirect costs used a control group of individuals without COPD. ${ }^{10,14,15}$ Analyses that stratify indirect costs by disease severity and exacerbation frequency would also help clarify the indirect costs that are specifically attributable to COPD.

Finally, interventions that might impact indirect costs, such as coordinated efforts between health care providers and large employers to improve COPD management, are largely unstudied. For example, productivity may be impacted by shortness of breath and other COPD symptoms, but there have been no studies of the impact of optimal COPD pharmacotherapy on worker productivity. Several pharmacotherapies improve exercise capacity in COPD, and research that explores this relationship from a work productivity standpoint would help identify strategies for managing the indirect cost burden of COPD. ${ }^{27}$

\section{Conclusion}

The indirect costs of COPD are substantial and the total national burden may be underestimated, in part due to the large proportion of individuals with undiagnosed COPD. Indirect costs impose a burden on employers in terms of productivity losses, absenteeism, impaired work performance, and disability claims and on individuals in terms of lost income and work and activity limitations, all of which lead to lower quality of life. Further studies are needed to assess the indirect burden of COPD, including analyses that use more recent data, take into account disease severity, and determine the burden of COPD on family caregivers. Finally, disease-specific interventions to manage the productivity loss associated with COPD and minimize the burden on individuals and employers need to be developed and tested.

\section{Acknowledgment}

The authors thank Judith S Hurley, MS, for editorial assistance.

\section{Disclosure}

Jeetvan G Patel, Saurabh P Nagar and Anand A Dalal are employees of GlaxoSmithKline (GSK); Jeetvan G Patel and Anand A Dalal own GSK stock. The authors have no other conflicts of interest to declare.

\section{References}

1. National Heart, Lung, and Blood Institute. Morbidity and Mortality: 2012 Chart Book on Cardiovascular, Lung and Blood Diseases. Bethesda: National Institutes of Health; 2012.

2. Hoyert DL, Xu JQ. Deaths: preliminary data for 2011. Natl Vital Stat Rep. 2012;61(6):1-65.

3. Toy EL, Gallagher KF, Stanley EL, Swensen AR, Duh MS. The economic impact of exacerbations of chronic obstructive pulmonary disease and exacerbation definition: a review. COPD. 2010;7(3):214-228.

4. Dalal AA, Shah M, D'Souza AO, Rane P. Costs of COPD in the exacerbations in the emergency department and inpatient setting. Respir Med. 2011;105(3):454-460.

5. Wang PS, Beck A, Berglund P, et al. Chronic medical conditions and work performance in the health and work performance questionnaire calibration surveys. J Occup Environ Med. 2003;45(12):1303-1311.

6. National Heart, Lung, and Blood Institute. Morbidity and Mortality: 2009 Chart Book on Cardiovascular, Lung and Blood Diseases. Bethesda: National Institutes of Health; 2009

7. US Bureau of Labor Statistics [webpage on the Internet]. Measuring price change for medical care in the CPI. NE Washington: US Bureau of Labor Statistics; 2010. Available from: http://www.bls.gov/cpi/cpifact4 htm. Accessed February 7, 2014.

8. Ward MM, Jasvitz HS, McFate Smith W, Whan MA. Lost income and work limitations in persons with chronic respiratory disorders. J Clin Epidemiol. 2002;55(3):260-268.

9. Mannino DM, Homa DM, Akinbami LJ, Ford ES, Redd SC. Chronic obstructive pulmonary disease surveillance: United States, 1971-2000. MMWR Surveill Summ. 2002;51(6):1-16.

10. Sin DS, Stafinski T, Ng YC, Bell NR, Jacobs P. The impact of chronic obstructive pulmonary disease on work loss in the United States. Am J Respir Crit Care Med. 2002;165(5):704-747.

11. Halpern MT, Stanford RH, Borker R. The burden of COPD in the USA: results from the Confronting COPD survey. Respir Med.2003; 97(SupplC): S81-S89. 
12. DiBonaventura MD, Paulose-Ram R, McDonald M, et al. The impact of COPD on quality of life, productivity loss, and resource use among the elderly United States workforce. J COPD. 2012;9(1):46-57.

13. Strassels SA, Smith DH, Sullivan SD, Mahajan PS. The cost of treating COPD in the United States. Chest. 2001;119(2):344-352.

14. Nair K, Ghushchyan V, Van Den Bos J, et al. Burden of illness for an employed population with chronic obstructive pulmonary disease. Pop Health Mgmt. 2012;15(5):267-275.

15. Darkow T, Kadlubek PJ, Hemal S, Phillips AL, Marton JP. A retrospective analysis of disability and its related costs among employees with chronic obstructive pulmonary disease. J Occup Environ Med. 2007;49(1):22-30.

16. Leigh JP, Romano PS, Schenker MB, Kreiss K. Costs of occupational COPD and asthma. Chest. 2002;121(1):264-272.

17. Goetzel RZ, Hawkins K, Ozminkowski RJ, Wang S. The health and productivity cost burden of the "top 10" physical and mental health conditions affecting six large US employers in 1999. J Occup Environ Med. 2003;45(1):5-14.

18. Williams SJ, Bury MR, "Breathtaking": the consequences of chronic respiratory disorder. Int Disabil Stud. 1989;11(3):114-120.

19. Yawn BP, Raphiou I, Hurley JS, Dalal AA. The role of fluticasone propionate/salmeterol combination therapy in preventing exacerbations of COPD. Int J Chron Obstruct Pulmon Dis. 2010;5:165-178.

20. Dalal AA, Shah M, Lunacsek O, Hanania NA. Clinical and economic burden of depression/anxiety in chronic obstructive pulmonary disease patients within a managed care organization. COPD. 2011;8(4): 293-299.
21. Dalal AA, Shah M, Lunacsek O, Hanania NA. Clinical and economic burden of patients diagnosed with COPD with comorbid cardiovascular disease. Respir Med. 2011;105(10):1516-1522.

22. Peytremann-Bridevaux I, Staeger P, Bridevaux PO, Ghali WA, Burnand B. Effectiveness of chronic obstructive pulmonary diseasemanagement programs: A systematic review and meta-analysis. Am J Med. 2008;121:433-443.

23. Lemmens KM, Nieboer AP, Huijsman R. A systematic review of integrated use of disease-management interventions in asthma and COPD. Respir Med. 2009;103(5):670-691.

24. Dewan NA, Rice KL, Caldwell M, Hilleman DE. Economic evaluation of a disease management program for chronic obstructive pulmonary disease. COPD. 2011;8(3):153-159.

25. Pinto-Plata V, Divo M, Celli BR. Treatments to alter the natural history of COPD. Pulmonary, Critical Care, Sleep Update (PCCSU). 2010;24, lesson 10

26. Global Strategy for Diagnosis, Management, and Prevention of COPD. Global Initiative for Chronic Obstructive Pulmonary Disease. 2014. Available from: http://www.goldcopd.org/uploads/users/files/ GOLD_Report2014_Feb07.pdf. Accessed February 7, 2014.

27. Restrepo RD. A stepwise approach to management of stable COPD with inhaled pharmacotherapy: a review. Respir Care. 2009;54(8): 1058-1081.

\section{Publish your work in this journal}

The International Journal of COPD is an international, peer-reviewed journal of therapeutics and pharmacology focusing on concise rapid reporting of clinical studies and reviews in COPD. Special focus is given to the pathophysiological processes underlying the disease, intervention programs, patient focused education, and self management protocols.

\section{Dovepress}

This journal is indexed on PubMed Central, MedLine and CAS. The manuscript management system is completely online and includes a very quick and fair peer-review system, which is all easy to use. Visit http://www.dovepress.com/testimonials.php to read real quotes from published authors. 